
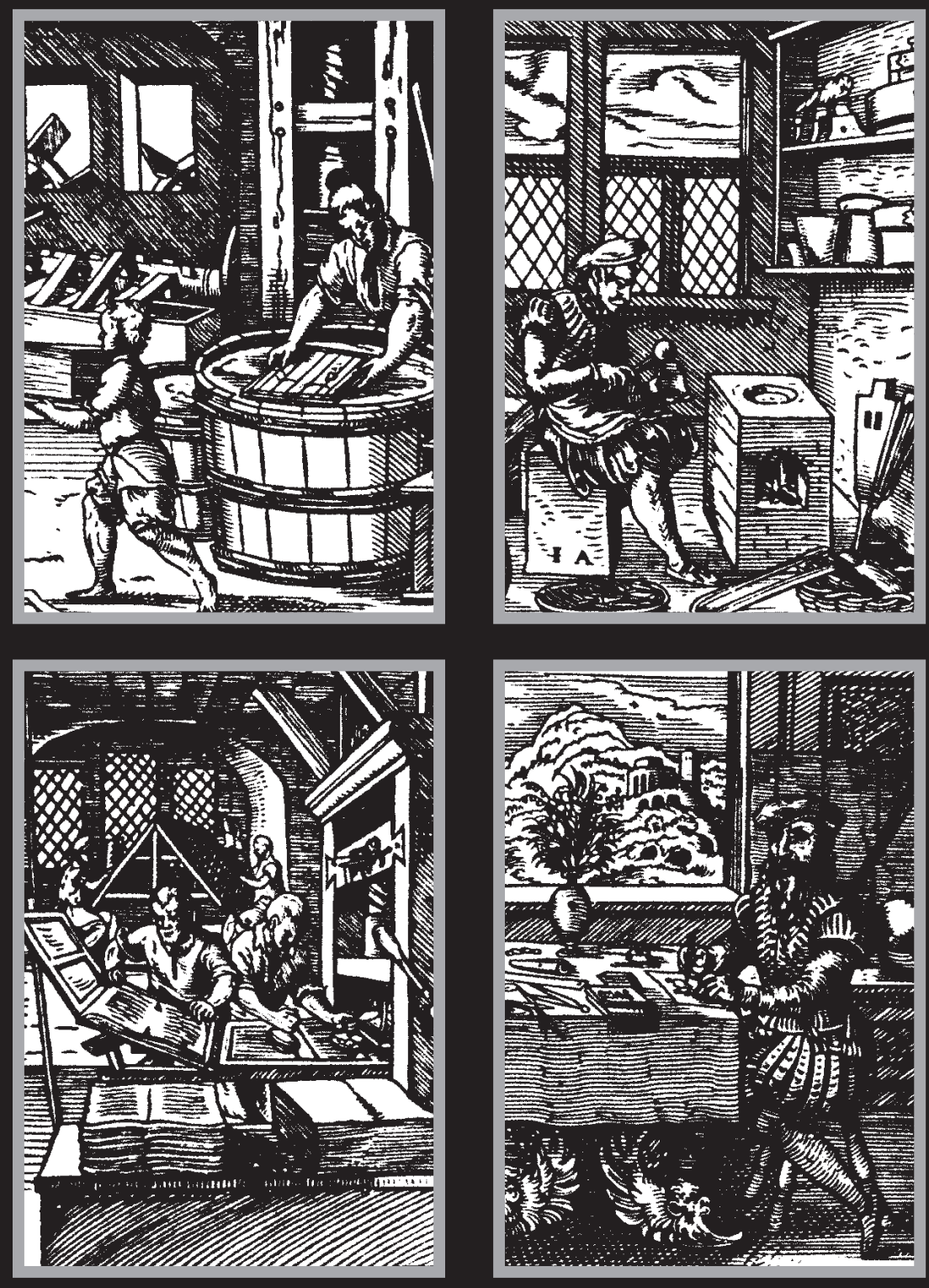

(1)
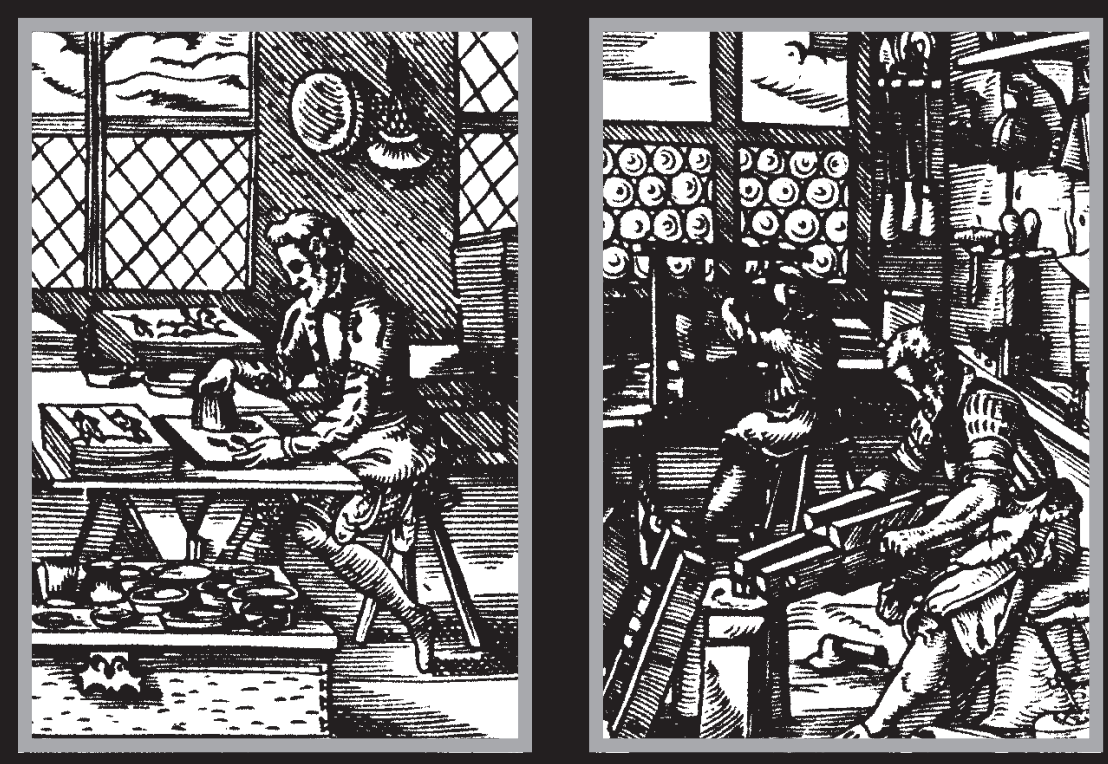


\section{Paradigmas jornalísticos}

\section{que floresceram precocemente}

\section{nas Américas: as}

contribuições

\section{seminais de}

\section{MARCO HISTÓRICO}

Desde que se constituíram como estados politicamente autônomos, no início do século XIX, as nações latino-americanas foram se desenvolvendo intelectualmente sob o estigma da exclusão comunicacional (1). Tal situação reproduzia em grande estilo o modelo de sociedade cultivado pelo regime colonial, tanto sob a égide dos castelhanos quanto dos lusitanos, tendo continuidade durante o regime independente, sob o comando das oligarquias crioulas.

Não obstante contassem com meios impressos de comunicação governados pela doutrina da liberdade de expressão e pensamento, as repúblicas hispano-americanas e o impé-

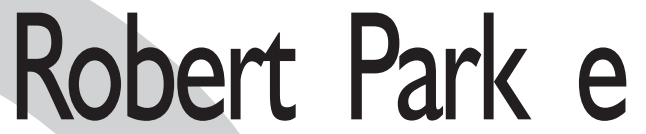

Barbosa Lima

Sobrinho

MELO é professor emérito

da ECA-USP, onde coordena o grupo de estudos "Pensamento Jornalístico Brasileiro". Atualmente é titular da cátedra Unesco de Comunicação na

rio luso-brasileiro consolidaram moUniversidade Metodista de São Paulo.

delos informativos erigidos como privilégiodas elites. Considerandoque os grandes contingentes das populações nacionais eram formados pelos trabalhadores iletrados, livres ou escravos, vivendo no campo ou nas cidades, a mídia impressa se converteu historicamente em espaço desfrutado apenas osé Marques de Melo "Exclusión Comunicacional y Democracia Mediática: Dilema Brasileño en el Umbral de la Sociedad e la Información", in Telos - Cuadernos de Comunicación, Tecnología y Sociedad, 51, Madrid, Fundación Telefónica, 2001, pp. 28-32 


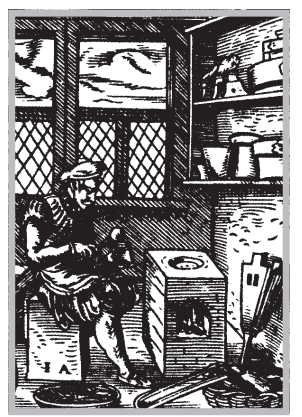

pelas classes superiores, incluindo as camadas médias beneficiadas pelos conhecimentos adquiridos na escola.

Trata-se de panorama contrastante com aquele que vigorou nos territórios de colonização anglo-americana. Neles predominou não apenas um padrão diverso de sociedade, em grande parte edificado pelo voluntarismo típico dos dissidentes religiosos, mas sobretudo uma postura civilizatória robustecida pela crença utópica na educação. Isso garantiu, desde cedo, o funcionamento de escolas, bibliotecas, imprensas e outros mecanismos destinados a fomentar a circulação de novidades, conhecimentos ou idéias. Dessa maneira, foi possível a tais colônias européias, fincadas no norte da América, através da inclusão comunicacional, unificar estratégias precoces de libertação do jugo colonial, exercitando formas de governo sintonizadas com os preceitos da democracia representativa. Para tanto, foi necessário fortalecer redes midiáticas, com a função de integrar politicamente as comunidades unificadas, bem como de assimilar culturalmente os imigrantes procedentes de várias partes do mundo, cuja força de trabalho converteu a jovem nação em potência econômica.

A situação intelectual das nações latino-americanas começaria a ser modificada no século XX, através das políticas públicas destinadas à universalização do sistema educacional. Adotadas em poucos países, mesmo assim elas abrangeriam preferencialmente as populações residentes nos centros metropolitanos. O processo de redução da marginalidade comunicacional das grandes massas sul-americanas somente seria alterado com o incremento das tecnologias eletrônicas de difusão simbólica. A expansão do rádio (a partir dos anos 30) e o desenvolvimento da televisão (a partir dos anos 50) ensejam oportunidades para a melhoria do apetite cognitivo das populações economicamente ativas. Até mesmo os contingentes analfabetos seriam promovidos à condição de consumidores culturais dos produtos sonoros ou audiovisuais disseminados pelas redes abertas, porque acessíveis a baixo custo.
Estamos ingressando no século XXI, podendo celebrar, na geografia americana, cinco séculos de institucionalização midiática. Contudo, o mapa da exclusão comunicacional permanece substancialmente inalterado ao sul do Rio Grande. Do México à Patagônia, continuam a vigorar panoramas caracterizados pelo pauperismo cultural das grandes massas. Elas estão geralmente distanciadas ou foram precocemente expulsas das redes educativas formais. Os maiores contingentes humanos da América Latina se nutrem de conhecimentos efêmeros, fragmentados e superficiais somente propiciados pelas "escolas paralelas" que brotam das redes midiáticas. Engrossando a categoria dos cidadãos de segunda classe, eles se tornam ineficazes ou inapetentes no sentido de atuar democraticamente como sujeitos da sua própria história.

Transformar essa realidade injusta constitui o maior enigma dos estudiosos da mídia massiva em nossas sociedades. Por isso mesmo constitui um bom exercício intelectual a comparação das situações perfiladas nos dois subcontinentes: o anglo-americano e o latino-americano. Para tanto, vamos tomar como referência os paradigmas construídos pelos precursores da midiologia nos dois extremos das Américas.

Devemos reconhecer, com humildade, que, apesar de um século de acumulação de conhecimentos midiológicos, a "esfinge midiática" ainda não foi "decifrada" pelas nossas comunidades acadêmicas. Por isso, acreditamos ser oportuna a retomada daqueles "paradigmas comunicacionais" que germinaram pioneiramente nas Américas, ao norte e ao sul. Temos a esperança de que essa incursão exploratória possa iluminar o desvendamento e a crítica dos demais paradigmas que floresceram contemporaneamente.

Povoando o imaginário daqueles que se devotam ao seu estudo e compreensão, nas empresas e nos governos, na academia ou na sociedade civil, a "esfinge midiática” permanece como uma ameaça capaz de "devorar” as nossas sociedades. Diante disso, não resta alternativa senão esboçar hipóteses e promover pesquisas, tentando superar os temores que nos afligem coletivamente. 


\section{PARADIGMA ANGLO-AMERICANO}

Não obstante os norte-americanos devam a John Dewey e Charles Cooley as primeiras reflexões acadêmicas sobre o papel social desempenhado pelos sistemas midiáticos,é sem dúvida Robert Park o precursor da midiologia nos Estados Unidos da América (2). Sua tese de doutorado A Multidão e o Público, defendida em Berlim, em 1904 (3), contém a essência do paradigma comunicacional anglo-americano: a notícia como forma de conhecimento.

Park supera a visão conservadora dos teóricos sociais europeus. Gabriel Tarde, por exemplo, limitou-se a descrever a influência da imprensa nas conversações interpessoais, expressando reservas no tocante à ingerência midiática na vida privada Ortega y Gasset, por sua vez, manifestou solene espanto diante do perigo de "rebelião das massas".

Demonstrando atitude progressista, Park valorizou o papel da mídia como agência socializadora por excelência. Reconheceu-a como dínamo do novo fenômeno da moderna sociedade, ou seja, a opinião pública. De acordo com sua análise, a mídia impressa e posteriormente os meios eletrônicos de comunicação poderiam desempenhar papéis decisivos na transformação de multidões amorfas e apáticas em públicos articulados e ativos, fortalecendo o sistema democrático (4).

Equacionando de maneira não-apocalíptica o desempenho das indústrias midiáticas na edificação da "sociedade de massa", Park e seus discípulos da Escola de Chicago (5) contribuíram decisivamente para a formulação da doutrina da "responsabilidade social", cuja dupla face preserva a “auto-regulamentaçãoempresarial” ea “educação dos profissionais". Ao Estado corresponde uma postura de não-intervenção no negócio midiático, assegurando seu desenvolvimento de acordo com os princípios da "livre iniciativa", consensuada através de "códigos deontológicos" capazes de coibir abusos ou desvios. À sociedade civil compete a formação dos agentes produtores dos conteúdos difundidos pelos veículos responsáveis por abastecer as "multidões" de conhecimentos destinados a convertê-las em "públicos" organicamente estruturados.

Vale a pena recordar que a participação das universidades nesse processo ocorre sintomaticamente quando a imprensa de massas envereda pela distorção "sensacionalista". As iniciativas pioneiras das universidades de Missouri e de Colúmbia destinadas a formar jornalistas responsáveis datam da primeira década do século XX (6), reproduzindo-se e multiplicando-se em todo o território norte-americano, quase sempre através de parcerias com as empresas a que se destinam os recursos humanos ali educados.

Foi através da formação de jornalistas, cineastas, publicitários, relações-públicas, radialistas ou teledifusores que as universidades influíram na consolidação do modelo midiático norte-americano. A partir dos anos 30, elas teriam papel decisivo na orientação das políticas de conteúdo, produzindo conhecimento cientificamente legitimado nos escritórios de pesquisa organizados para atender às demandas empresariais. Tais oficinas investigativas também atenderiam a clientes governamentais, ou seja, as agências responsáveis pela formulação e avaliação das políticas públicas, sequiosas de dados confiáveis sobre o impacto social da mídia (7).

Contudo, para compreendermos com clareza a eficácia do paradigma anglo-americano (8), situando a mídia como forma de conhecimento, torna-se indispensável mencionar as variáveis intervenientes no processo. Uma delas é o paralelismo entre o desenvolvimento dos sistemas midiático e educativo, em todos os quadrantes do território nacional. A universalização das oportunidades de ensino-aprendizagem, oferecendo educação formal básica a todos os cidadãos, constituiu, ao longo do tempo, uma prioridade da sociedade industrial construída pelos norte-americanos. Assim sendo, as novas gerações de usuários dos sistemas midiáticos geralmente possuem escolarização suficiente para demandar conteúdos mais bem elaborados. Mas elas

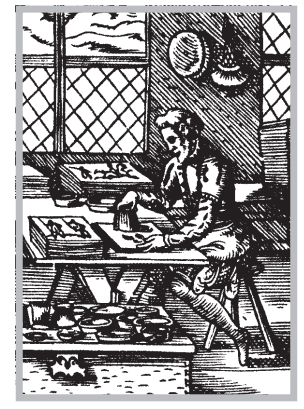

2 Daniel J. Czitrom, Media and the American Mind - from Morse to Mcluhan, Chapell Hill, University of North Caroline Press, 1982, pp. 91-121.

3 A versão original Masse und Publikum (1904) somente foi traduzida para o inglês em 1972 sob o título The Crowd and the Public (University of Chicago Press).

4 Embora essa concepção estivesse implícita na tese de 1904 Park somente a explicita no artigo "A Notícia como Forma de Conhecimento" publicado na edição 45 do The American Journal of Sociology (Chicago University, março de 1940

5 O protagonismo de Robert Park no bojo da Escola de Chicago está bem dimensionado no ensaio de Alain Coulon, L'Ecole de Chicago Paris, Presses Universitaires de France, 1992).

6 Para uma melhor compreensão desse episódio histórico, vale a pena consultar o ensaio de Carlos Rizzini, O Ensino de Jornalismo (Rio de Janeiro, Ministério da Educação, 1953).

7 inventário dos projetos mais importantes realizados pela academia norte-americana está contido no livro de Shearon Lowery e Melvin De Fleur, Milestone in Mass Communication Research 13 a ed. New York, Logman, 1994

8 A moldura do paradigma norte-americano pode ser percebida através dos instantâneos contidos no livro George N. Gordon, The Communications Revolution a History of Mass Media in the United States (New York, Hastings House, 1979| 
9 Os paradoxos do consumo cultural na sociedade norteamericana podem ser vislumbrados com nitidez no ensaio de AlvinTofler, The Culture Consumers: Art and Afluence in América (Baltimore, Penguin Books, 1965).

10 Por isso mesmo, Marshal Mcluhan, em seu livro de estréia, The Mechanical Bride (Boston, Beacon Press, 1951). não hesita em proclamar que ali está presente o "folclore do homem industrial".

11 Para uma visão panorâmica do universo popular apropriado pela indústria midiática norte americana, vale a pena consutar a antologia organizada por lack Nachbar e Kevin Luase, Popular Culture, and Introdutor Text Bowling Green, Ohio Bowling Green State University Popular Press, 1992).

$12 \mathrm{~A}$ comparação entre cultura popular e cultura erudita na mídia norte-americana fo esboçada por Herbert]. Gans, Popular Culture and High Culture, and Analysis and Evaluation of Taste (New York, Basic Books, 1974).

13 A convocação feita por Park ecoaria fortemente na comunidade acadêmica, como bem o documenta Christophere Brookeman no livro American Culture and Society since 1930s (New York, Schoken Books, 1984)

14 Essas teses estão esbocadas no artigos "News and the Powe of the Press" (julho de 1941) e "Morale and the News" Inovembro de 1941), ambos publica dos no American Journal of Sociology.

150 exercício típico da crítica midiática vigente na socieda de norte-americana corresponde ao padrão cultivado pelo colunista Howard Kurtz, cuios comentários publicados no jor nal The Washington Post motivaram o livro Media Circus New York, Handon House 1993)

16 Essa corrente foi sensivelmente estimulada, na academia, pe los textos escritos por vigorosos intelectuais críticos como HerbertSchiller /Mass Meid and the American Empire, Boston, Beacon Press, 1970), J. Herber Altschull (Agents of Power, New York, Longman, 1984l e Bem Bagdikian Media Monopoly, Boston, Beacon Press, 1990| são educadas livremente, tendo capacidade de optar pelos produtos que satisfaçam suas necessidades imediatas, geralmente ditadas pelos padrões culturais das comunidades que integram no dia-a-dia (9).

Na própria escola, os futuros cidadãos são induzidos a assumir atitude crítica, participando de processos de "alfabetização midiática”, da mesma forma que vivenciam experiências de "alfabetização científica" ou de "alfabetização artística". Ao invés de demonizar a mídia, os educadores norte-americanos geralmente a tomam como um dado inerente à realidade que as crianças vão encontrar na vida adulta. Sem preconceito, eles propiciam aos seus alunos noções sobre a engrenagem midiática. Buscam, ao mesmo tempo, referentes didáticos nos jornais ou na televisão, da mesma forma que o fazem em relação à literatura ou à biologia, como estratégia de motivação pedagógica.

Isso decorre da fina sintonia entre a agenda midiática e a vida cotidiana do conjunto das classes sociais que compõem o mosaico norte-americano. A indústria do entretenimento, especialmente o cinema, a televisão e as histórias em quadrinhos, desde o seu nascimento, focalizou temas e personagens vinculados à cultura popular (10). As cenas contidas nos filmes de farwest, os dramas suburbanos difundidos a conta-gotas nos capítulos das soap-opera, as lendas rurais estilizadas nos cartoons, os conflitos típicos dos bolsões racistas enquadrados nas sitcom, etc., constituem evidências dessa constante retroalimentação entre mídia massiva e classes subalternas (11), da mesma forma que os jornais de prestígio refletem os gostos e desejos da inteligentzia (12).

Justamente pela composição plural, diversificada e bem dosada do seu conteúdo, correspondendo às expectativas de todos os segmentos sociais, é que a indústria midiática norte-americana pode atuar como "escola paralela". Ela vem funcionando historicamente como agência socializadora dos novos contingentes humanos que engrossam a população nacional, oriundos de todos os quadrantes do planeta. Essa fun- ção cognitiva da mídia mereceu alentado estudo de Robert Park durante seu estágio de inserção na vida acadêmica, logo após a fecunda experiência como jornalista e relações-públicas. Ao estudar o papel da imprensa comunitária na assimilação cultural dos trabalhadores imigrantes ele acrescentou novos ingredientes ao paradigma da mídia como forma de conhecimento.

Park foi também o responsável pela inclusão de um componente dialético nesse paradigma anglo-americano. Quando o explicitou formalmente no conjunto de artigos publicado no biênio 1940-41, ele advertiu a comunidade acadêmica em relação aos perigos contidos na engrenagem midiática, quando esta passava a se converter numa fonte de poder. Ao expressar reservas em relação ao tipo "expressivo" de conteúdo midiático ele concitava seus colegas de academia a exercer uma espécie de vigilância cidadã (13). Sua sinalização objetivava neutralizaros efeitos nefastos dos produtos destinados ao entretenimento coletivo, no bojo dos quais ele identifica "influência cultural subversiva", potencialmente causadora de “desorganização social” (14)

Na verdade, Robert Park lança as bases do movimento de autodefesa midiática, que viria a ser conhecido como midia criticism instituindo vigilantes de conteúdo no interior das indústrias midiáticas, ou seja, instâncias defensoras dos interesses dos consumidores culturais (15). Essa inserção transparente da vigilância midiática no corpo das edições disseminadas pelos veículos massivos representa sem dúvida o estímulo ao exercício crítico dos seus receptores. Trata-se de mecanismo capaz de propiciar o rompimento da solidão típica das multidões silenciosas, acelerando a consciência cidadã indispensável ao ativismo dos públicos antenados com o interesse coletivo e o bem-estar da sociedade (16).

\section{PARADIGMA LATINO-AMERICANO}

O exercício mais consistente de reflexão crítica sobre a emergente engrenagem midiática na América Latina foi empreen- 
dido, há 80 anos, pelo brasileiro Alexandre José Barbosa Lima Sobrinho. Seu livro $O$ Problema da Imprensa contém não apenas um preciso diagnóstico sobre o desenvolvimento da imprensa no mundo contemporâneo, mas uma interpretação acurada do impacto causado pela sua industrialização no perfil da sociedade brasileira. Sua sofisticada análise, transposta para quaisquer outros países da região, aplica-se, com ligeiros ajustes, aos respectivos quadros socioculturais

Por isso mesmo é que o arcabouço teórico construído pelo jovem Barbosa Lima Sobrinho (17) pode ser tranqüilamente referido como paradigma latino-americano. Argumentando com lucidez que o jornal reflete a sociedade em que se edita, ele oferece evidências que permitem enunciá-lo contemporaneamente da maneira seguinte: a imprensa é o espelho da sociedade.

Vamos retomar, textualmente, sua linha de raciocínio:

“[...] só me pergunto se a imprensa é culpada de todo os males que lhe imputam, ou autora de todos os benefícios que vai semeando com despreocupação. E só me acode a resposta de que vale como a peça indispensável de um maquinismo, forçada ao movimento de outras peças e ela própria fazendo girar, nos seus eixos, outras rodas Há jornais maus, dissemos; a imprensa, todavia,é boa. Confessemos que se acha ao alcance de fatores perniciosos, capazes de perturbarem a sua eficiência e de anularem a sua utilidade. De onde vem essa força perturbadora e nefasta? Do público, da própria imprensa e do governo.

Primeiramente do público, para que se faz o jornal. Ele manda nas gazetas e são as suas paixões, as suas tendências e idéias que a folha reflete como um espelho. Um autor nos diz que o jornal é mais dos seus leitores do que dos seus redatores, ou proprietários. Debalde se esforçaria uma imprensa para se avantajar ao povo a que servisse. As necessidades a obrigariam a encurtar tais distâncias e a aproximar-se de seus leitores. Se todos os jornais não se modelam por uma forma única, é que há a diferenciação das classes sociais, manifestada na imprensa. [...]

Há, em segundo lugar, a culpa do governo. [...] Não escapou o nosso país do flagelo. Conhecemos os processos da subvenção e os da concessão de favores, ou empregos . Encontrando-se sem o apoio da imprensa de partido, o governo corrompe jornalistas com que se defender. [...]

Por último, vemos a culpa dos próprios jornalistas. Alguns sentam praça na imprensa com o intuito premeditado das negociatas... [...] Não se lembra o jornalista, nas suas atitudes, de que está agindo como num palco, diante de um público atento e rigoroso. Desconhece que a sua missão social exige de sua parte compostura; ignora muitas vezes que deve servir a causa pública, sacrificando-lhes as suas questões pessoais e inimizades" (18).

A prescrição que o pensador brasileiro sugere para o combate às mazelas, desvios e distorções da mídia demonstra uma clarividente postura democrática e uma fidelidade consentânea com o paradigma esboçado. Ele não pretende atropelar as leis da ótica para ajustar os vieses das imagens captadas ou refletidas de modo inexorável nos espelhos midiáticos. A solução está na mudança e ajuste dos personagens, cenários e movimentos que dão sentido à realidade, para que esta venha a aparecer de modo correto, aperfeiçoando-se constantemente.

Sua estratégia comporta ações simultâneas e articuladas: elevar o nível cultural do público, regulamentar osfluxos midiáticos, além de educar os produtores de conteúdo.

Façamos o percurso dessas terapias de acordo com suas próprias palavras:

1)“Há defeitos incorrigíveis na imprensa e diante dos quais é preciso cruzar os braços, pelo receio dos danos imensos que qualquer intervenção acarretaria. Esclareça-se o espírito público, difunda-se a instrução e entregue-se à educação o preparo de caracteres; à medida que esse esforço venha atuando, a imprensa naturalmente se elevará" (19).

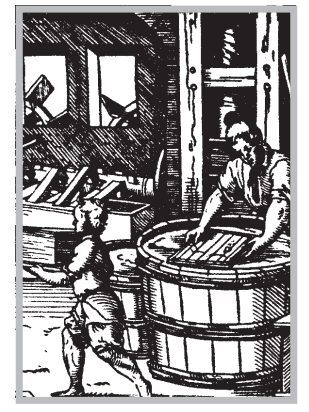

17 Estreando no jornalismo aos 22 anos de idade, Barbosa lima Sobrinho cedo foi guindado à função de repórter parlamentar do Jornal do Brasil e depois elevado à condição de redator-chefe desse jornal brasileiro de referência nacional. $O$ ensaio escrito em 1923 contém uma lúcida reflexão sobre a profissão que decidiu exercer, fundamentando-se conceitualmente na bibliografia internacional disponível, embora sua referência empírica tenha se ancorado na trajetória histórica da mprensa brasileira, cujas prá ticas e agentes the serviram como parâmetros para elucidar o "problema da imprensa"

18 Barbosa Lima Sobrinho, O Problema da Imprensa, $2^{2}$ ed. . São Paulo, Edusp, 1988, pp. 16970 |Coleção Clássicos do Jornalismo Brasileiro, 1)

$191 \mathrm{dem}$, ibidem, p. 171 


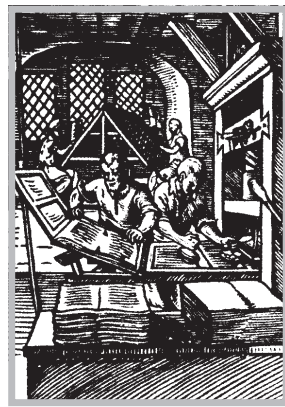

2) "Convém igualmente agir sobre a imprensa, mas não com uma legislação drástica. A prudência, que dirige os homens sábios, desaconselha os meios violentos. [...] Lei sensata será aquela que evitar à imprensa todo o perigo da violência e da injustiça, garantindo-a na sua liberdade e nos seus direitos para que entibie a sua ação social pelo receio das penalidades" (20).

3) "Mas não basta ter uma lei. Há outros meios úteis. Os americanos instituem escolas de jornalistas, para o preparo de profissionais competentes, uma vez que à ignorância cabe tanta parte da culpa dos males da imprensa. Eles também usam os congressos em que se dispõem preceitos de ética para o governo de todos" (21).

O pensador brasileiro reafirmaria suas teses cinco décadas depois. Em conferência proferida no ano de 1971 , ele insistia na defesa de que a imprensa só pode avançar politicamente se o povo também evoluir intelectualmente. “[...] à medida que o povo se esclareça, a imprensa se verá forçada a acompanhá-lo, nem faltarão as vozes condutoras, para apontar os roteiros indispensáveis ao seu progresso e ao seu desenvolvimento" (22). Sua descrença na solução do problema da imprensa através de legislação coercitiva seria reiterada na conferência que proferiu em 1980 perante a VIII Conferência Nacional da Ordem dos Advogados do Brasil: "O medo da liberdade de imprensa, o medo de seus excessos, é o caminho mais fácil para o reduto das ditaduras" (23).

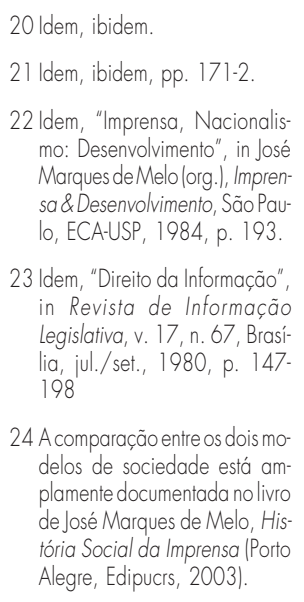

24 A comparação entre os dois modelos de sociedade está amplamente documentada no livro de José Marques de Melo, História Social da Imprensa (Porto Alegre, Edipucrs, 2003)

Quando Barbosa Lima Sobrinho formulou as teses que embasam o paradigma latino-americano da imprensa como espelho da sociedade, ele naturalmente tomava como pressuposto o paradigma anglo-americano da notícia como forma de conhecimento. E por que não o assimilou integralmente em sua formulação? Ou somente in- corporou parte dele, isto é, o aspecto referente à educação dos produtores midiáticos? Ele assim procedeu porque seu exercício analítico considerava o contraste dos dois modelos de sociedades.

As nações anglo-americanas foram moldadas de acordo com projetos sociais inclusivos, beneficiando majoritariamente seus contingentes populacionais com um tipo de formação cultural protagonizada simultaneamente pela escola e pela mídia. Diferentemente, as sociedades latino-americanas assumiram perfis socioculturais excludentes, marginalizando os vastos contingentes nativos ou mestiços. Estes permaneceram sem direito a escola e conseqüentemente também sem condições de acesso aos produtos simbólicos de qualidade difundidos pela mídia. Além disso, estava implícita a comparação dos respectivos perfis sociopolíticos. As primeiras se afirmavam precocemente como nações (século XVIII), inspiradas nos ideais da democracia representativa. Por isso, atribuíram à mídia a função de "quarto poder", estabelecendo não só um regime de coexistência com a máquina governamental, mas impedindo-a constitucionalmente de criar obstáculos para a sua livre expressão.

De forma contrastante, as sociedades latino-americanas viriam a se perfilar tardiamente (século XIX) como nações independentes. Optando por sistemas autoritários de organização política, reproduziram os modelos aristocráticos ibéricos. Em função disso, conferem à mídia impressa e depois à mídia eletrônica um papel de controle social difuso. Emerge daí a fúria legiferante que assola os detentores do poder, tratando de criar filtros midiáticos, manietando seus proprietários ou corrompendo seus profissionais (24).

Não é sem razão que Barbosa Lima
Sobrinho defende a vigência de leis sensatas, capazes de regular os abusos cometidos pela mídia, sem contudo inibir o seu funcionamento livre e contínuo. Quando ele resgata a tradição norte-americana dos "códigos de ética" o faz com reservas, tendo em vista o "ceticismo" imperante em nossas sociedades nacionais. 
Afigurando-se ineficaz o exercício da auto-regulamentação, torna-se necessário o arbítrio do poder público, através de mecanismos transparentes de conduta, punindo a posteriori os respectivos infratores. Como "espelho da sociedade" a mídia só pode ter referentes mais elevados à medida que tanto os consumidores quanto os produtores forem mais bem educados.

A educação dos consumidores repousa decisivamente na universalização da escola básica, nutrindo a população daqueles referentes culturais capazes de demandar melhores conteúdos. Enquanto perdura esse processo de crescimento do nível cultural da sociedade, compete aos produtores midiáticos proporcionar agenda e conteúdos sintonizados com as preferências e gostos populares. Contribuindo para a sua elevação gradativa, espera-se que eles não agravem, ainda mais, a bola de neve da exclusão comunicacional .

Esta é uma variável do "problema midiático", tal qual descrito pelo latinoamericano Barbosa Lima Sobrinho, a merecer atenção particular dos pesquisadores acadêmicos. Em seu diagnóstico ele transfere a questão diretamente aos profissionais midiáticos, recomendando sua "educação universitária”, como já vinham ensaiando os norte-americanos desde o início do século XX.

Isto só viria a se generalizar na América Latina na segunda metade do mesmo século, coincidindo com a transformação das próprias universidades. Estas já haviam superado a fase de treinamento puro e simples da mão-de-obra destinada ao comércio, à indústria e ao serviço público, convertendose também em agências produtoras de conhecimento (25). A pesquisa se incorporava à rotina dos seus laboratórios e os novos profissionais incorporavam as inovações científicas à sua bagagem intelectual.

A equação midiática se tornara evidentemente mais complexa, tendo em vista os mecanismos criados pela pesquisa social para auscultar com precisão e sensibilidade as demandas populares. Sendo possível esse reconhecimento prévio das necessidades dos consumidores, cabe aos produto- res, hoje superiormente educados, controlar seus ímpetos voluntaristas (quase sempre dotados de matizes elitistas), deixando-as pautar as agendas midiáticas. Ou melhor, não pretendendo impô-las, de acordo com posturas salvacionistas ou ideários culturalistas, quase sempre justificados como parte de sua missão "civilizatória".

A grande dificuldade latino-americana para estabelecer sintonia entre a agenda construída pelos produtores midiáticos e as expectativas das correntes majoritárias dos consumidores culturais está na ausência de pesquisa sistemática que ilumine as motivações da audiência. Como as empresas privadas que realizam ratings periódicos se limitam a mensurar os hábitos de consumo, caberia aos centros de pesquisa das universidades desvendar essa "caixapreta", evitando que se transfiram mecanicamente para as nossas sociedades as concepções teóricas importadas das sociedades do norte, como se elas fossem aplicáveis às nossas realidades .

Munidos de conhecimentos dessa natureza, poderíamos estar atuando em duas frentes: 1) formando competentemente os profissionais que vão atuar na produção e gestão das indústrias midiáticas; 2) realizando experiências nos laboratórios das próprias universidades para criar novos formatos e conteúdos midiáticos consentâneos com as expectativas simbólicas e os gostos estéticos das grandes faixas culturalmente pauperizadas da audiência.

Se assim procedêssemos, estaríamos contribuindo positivamente para reduzir a "brecha cultural" existente em nossos países, dando um passo à frente do paradigma comunicacional que cultivamos. Ou seja, deixaríamos de contemplar solenemente as nossas sociedades no espelho midiático para tentar transformá-las, ajudando a elevar o nível cultural das nossas populações e concomitantemente criando fluxos interativos contínuos entre as audiências e os produtores de conteúdo.

A pesquisa comunicacional latino-americana tem feito, nas últimas décadas, incursões significativas para compreender as mediações culturais (26) exercidas pelas

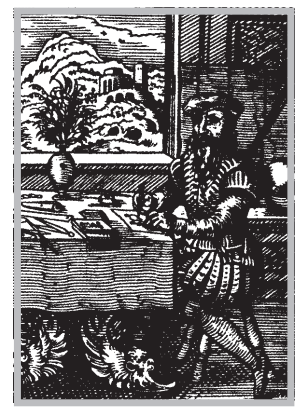

25 As singularidades latino-americanas estão esboçadas no capítulo "A Natureza do Conhecimento Midiológico" do livro de José Marques de Melo, História do Pensamento Comunicacional (São Paulo, Paulus, 20031.

26 A fonte inspiradora de tais pesquisas tem sido inegavelmente o livro de Jesus Martín-Barbero, De los Medios a las Mediaciones/México, Gustavo Gili, 1987). 
27 llustra adequadamente essa cor rente o conjunto das alternatvas sugeridas por Mercedes Charles e Guillermo Orozco na coletânea Educación para la Recepción: Hacia uma Lectura Crítica de los Medios (México, Trillas, 1990) ou os roteiros ela borados por Ismar de Oliveira Soares, Para uma Leitura Crítcados Jornais, 1984, Para uma Leitura Crítica da Publicidade 1988 (São Paulo, Edições Paulinas|

28 Tais mecanismos de resistência cultural e de ressocialização intensiva foram amplamente estudados por Luiz Beltrão em seus livros: Folkcomunicação um Estudo dos Agentes e dos Meios Populares de Informacão de Fatos e Expressão de Idéias (2 ed., Porto Alegre, Edipucrs 2001): e Folkcomunicação, Comunicação dos Marginaliza dos (São Paulo, Cortez, 1980)

29 Um bom itinerário para encetar essa cruzada em direção ao conhecimento do gosto popular está contido no livro de Jesus Martín-Barbero, Procesos de Comunicación y Matrices de Cultura IMéxico, Gustavo Gili, 1987).

30 Em certo sentido, essa foi tática empregada pela indús tria televisiva brasileira no processo de "substituição de importações" daqueles produtos audiovisuais outrora procedentes das fábricas norte-americanas. Presentemente os conte dos disseminados pelas redes brasileiras de televisão aberta no "horário nobre" (prime time são predominantemente nacionais. Quem descreve com a gúcia essa estratégia bem-su cedida é o escritor cubano-me xicano Mario Nieves (Televisión Bajo Palabra: Poder, Palabra Identidad em la TV Brasileña Monterrey, Universidad Regio montana, 2002

31 Esse legado está descrito nos três volumes que iniciam a série "Anais da Escola Latino-Americana de Comunicação": José Marques de Melo e Juçara Brittes, A Trajetória Comunic acional de Luiz Ramiro Beltrán 1998); José Marques de Melo e Paulo da Rocha Dias, $O$ Percurso Intelectual de Jesus Martín-Barbero (1999); e José Marques de Melo e Maria Cristina Gobbi, Gênese do Pensamento Comunicacional Latino-Americano (2000), publicados em parceria pela Unesco pela Umesp (São Bernardo do Campo, Brasill. agências socializadoras. Vem estudando como a família, a escola, a igreja ou as associações comunitárias ressemantizam os conteúdos alienígenas disseminados pela mídia, atribuindo-lhes sentidos identificados com os seus legítimos referentes simbólicos

Tais evidências estimularam projetos de “educação para a recepção" (27) que sem dúvida podem vir a influir na correção de desvios cometidos pelos segmentos mais bem apetrechados simbolicamente, redirecionando seus hábitos de consumo. Esses bolsões são geralmente constituídos por consumidores que possuem capacidade aquisitiva suficiente para demandar produtos de melhor qualidade, em fontes alternativas. Contudo, permanecem excluídos desse processo mudancista aqueles contingentes societários que habitam os cordões periféricos das grandes metrópoles. Geralmente constituídos por migrantes oriundos da zona rural, eles conservam padrões culturais que não se coadunam com os referentes disseminados pela rede escolar. Por isso, ficam à margem dos conteúdos difundidos pela mídia.Daí a necessidade de criar suas próprias redes de socialização (28) para poder sobreviver no novo ambiente em que foram condenados a habitar compulsoriamente.

Inegavelmente a estratégia mais adequada para preencher esse vácuo cognitivo está no deciframento daquelas "matrizes de cultura" (29) das classes subalternas. Num segundo momento, devemos convertê-las em artefatos simbólicos que possam vir a ser difundidos pelas indústrias midiáticas . E, dessa maneira, substituir gradativamente os conteúdos “importados", preferidos pelas audiências na falta de opções populares-nacionais (30). Ou então, ocupar o espaço daquelas mensagens "híbridas", geralmente produzidas na própria região. $\mathrm{Na}$ medida em que os seus referentes estão situados nas camadas superiores da sociedade, não podemos estranhar que elas sejam refugadas pelas correntes majoritárias da audiência. Trata-se em verdade de um mecanismo de defesa, pois o seu repertório intelectual não lhes permite desfrutá-las convenientemente.

\section{ROTEIRO DE LUTAS}

Para ingressar altivamente no século XXI, instaurando políticas comunicacionais historicamente fiéis ao legado dos nossos pioneiros (31), a comunidade latino-americana de ciências da comunicação defrontase com duas batalhas simultâneas: a batatha da cidadania e a batalha da academia.

Difícil, ampla e polifacética é sem dúvida a batalha da cidadania. Ela se opera no âmbito das sociedades nacionais, que precisam romper as estruturas ancestrais de exclusão social, no sentido de garantir oportunidades equânimes a todas as camadas da população para desfrutar os benefícios do progresso. Trata-se de uma batalha vigorosa contra a ignorância, que impede o florescimento das demandas de natureza cognitiva. Mas também de uma batalha contra o silêncio, que neutraliza o impulso à expressão individual e aos sentimentos coletivos. Seu território é predominantemente o da escola, onde as novas gerações precisam aprender a ler, a escrever e a contar, munindo-se de requisitos capazes de produzir e consumir informações cotidianamente. Para engajá-las no circuito da produção e consumo dos bens culturais, torna-se indispensável equacionar vários problemas conexos. Entre eles, o déficit das telecomunicações, garantindo aos neocidadãos o acesso universal às tecnologias digitais e aos provedores de serviços. Inclua-se, nesse panorama, o barateamento dos produtos da indústria de conteúdos culturais (livros, jornais, revistas, discos e similares) (32).

Aoeliminar a exclusão comunicacional, as sociedades latino-americanas estarão habilitadas a trilhar o caminho da elevação cultural das suas indústrias midiáticas e conseqüientemente forjar cidadãos que façam da democracia o instrumento da coexistência pacífica e da cooperação civilizatória (33).

Específica, embora sinuosa e resistente, tem sido a batalha da academia. Ela vem sendo travada no território das universidades. Seu inibidor contumaz tem sido a 
"síndrome do colonizado" que ainda marca a fisionomia de grande parte da nossa vanguarda intelectual. Para vencer essa batalha, superando a tendência ao comportamento isolacionista que nos tem enfraquecido, conduzindo, vez por outra, à inércia corporativa, devemos resgatar o compromisso histórico com a transformação das sociedades a que pertencemos.

Nesse sentido, gostaríamos de reiterar algumas metas, propostas ao debate da comunidade latino-americana de ciências da comunicação, durante o último congresso da Alaic (Santa Cruz de la Sierra, 2002) (34):

a) Natureza processual da comunicação. As tendências recentes de pesquisas centradas nas mediações (estudos de recepção), ideologia (análises de discurso) e mercadologia (marketing político) estão contribuindo para descaracterizar a comunicação como fenômeno coletivo. Torna-se imprescindível contemplar a comunicação como processo social, incentivando estudos sobre o comportamento dos emissores (mapas etnográficos ou sociográficos) e sobre os efeitos (impactos psicossociais, políticos, educativos), com a finalidade de influir na etapa de construção de novos produtos midiáticos. Trata-se de produzir conhecimento aplicável ou de fazer a crítica socialmente utilitária.

b) Autonomia teórica, fomentando a crítica metodológica. Trata-se de superar o reboquismo em relação às ciências sociais, assumindo nosso perfil de ciências aplicadas e recorrendo a estratégias investigativas que permitam estocar conhecimentos capazes de melhorar a qualidade dos produtos midiáticos demandados pela sociedade. Devemos preservar o diálogo com as ciências sociais, em condições equilibradas de parceria acadêmica, superando um certo complexo de inferioridade intelectual que fragiliza parcela hesitante da nossa comunidade.

c) Resgate do conhecimento empírico, em sua tríplice dimensão: autóctone, mestiço e popular. Infelizmente, tendemos a desdenhar tudo aquilo que é nativo, peculiar, rústico, ao mesmo tempo em que recusamos as demandas populares. Grande parte da tradição comunicacional latino-americana provém das adaptações metodológicas que fizemos de modelos importados e de soluções engenhosas que assimilamos das culturas populares. Na formação das novas gerações de comunicadores, devemos ter coragem suficiente para recorrer ao arsenal empírico estocado pelas corporações profissionais, ajudar a sistematizálo e atualizá-lo a partir do referencial crítico que sempre embasou o trabalho universitário.

Tais ofensivas podem ajudar a transformar aquela realidade injusta a que nos referimos inicialmente. E devemos começar pela superação do estado de quase atrofia a que se autocondenaram nossas comunidades acadêmicas. Inapetentes para o trabalho cooperativo, céticas em relação aos projetos holísticos, relutantes em reconhecer o mérito das gerações precedentes, envergonhadas diante da sua própria identidade, elas patinam dramaticamente, confusas diante do passado, descrentes em relação ao futuro.

Nessa conjuntura histórica, nosso maior desafio é a constituição negociada de uma comunidade pan-americana, regida pelo livre comércio, pelo multiculturalismo e pela coexistência democrática. Ela pode ser o nosso passaporte para desfrutar um lugar ao sol no novo mapa do mundo. Portanto, nada mais oportuno do que restaurar aquela solidariedade latino-americana, antevista de forma quase messiânica pelo antropólogo Darcy Ribeiro:

“[...] sobre nossos ombros recairá, em grande parte, a tarefa de criar uma nova ocidentalidade que seja, pela primeira vez, uma civilização humana respeitável. [...] só vejo a nós para a tarefa urgente de humanizar nossa civilização e orientá-la por caminhos solidários que livrem os homens do medo e lhes devolvam a alegria de viver" (35).

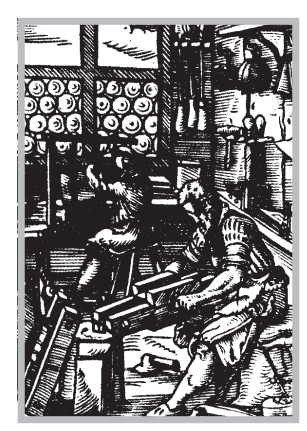

32 Tais questões encontram-se mais bem dimensionadas no ensaio de José Marques de Melo: "A Muralha Digital: Desafios Brasileiros para Construir uma Sociedade do Conhecimento", in Cićlia Peruzzo e Juçara Brittes, Sociedade da Informação e Novas Mídias: Participação ou Exclusão? (São Paulo, Intercom, 2002, pp. 37-44).

33 Esta batalha está dimensionada em todas as suas facetas no artigo de JoséMarques de Melo: "Exclusión Comunicacional y Democracia Mediática", in Telos 51 Madrid Fundación Telefónica, 2002, pp. 28-31.

34 José Marques de Melo, "Ciências da Comunicação na América Latina: Itinerário para Ingressar no Século XXI", in Memória do VI Congresso da Alaic (Santa Cruz de la Sierra, Bolívia, 20031

35 Darcy Ribeiro, América Latina, a Pátria Grande, 2ed., Rio de Janeiro, Guanabara, 1986, pp. $105-6$ 